\title{
Non-Destructive Electrical Methods to Determine the Quality of Concrete
}

\author{
By Sreekanta Das * \\ William Clements ${ }^{\dagger}$ \\ Govinda Raju
}

There is a great need to explore and develop non-destructive testing methods of concrete to ensure proper curing and it possesses required strength in construction and in service. Limited experiments using electrical methods have been reported in the literature to explore the relationship between the electrical properties and quality of concrete. This study was designed to develop experimental methods that employ the relationship between the electrical and mechanical properties of cement concrete. Concrete is an insulating material from the electrical point of view and large volume of theory and experimental techniques are available to study the insulating properties of materials used in electrical and electronic equipments. This study was oriented to examine whether those theories and experimental techniques, could be applied to concrete, with suitable modifications to its specific nature and properties. To facilitate this objective, several equivalent circuits were investigated to represent concrete as an insulating material. Simple measurement of resistivity alone has been undertaken by several previous investigators and it was felt, as confirmed by our own investigations, that this information is not sensitive enough. Therefore, a more sophisticated method based on fundamental electrical theory was developed. These experiments, conclusions drawn, proposal for a diagnostic method and possibility of future developments are discussed in this paper.

\section{Introduction}

Concrete is currently one of the most widely used construction materials making it one of the intensely researched materials in civil engineering. The most important parameter of concrete is the final compressive strength which it

\footnotetext{
*Associate Professor, Department of Civil and Environmental Engineering, University of Windsor, Canada.

${ }^{\dagger}$ Research Scholar, Department of Electrical and Computer Engineering, University of Windsor, Canada.

*Emeritus Professor, Department of Electrical and Computer Engineering, University of Windsor, Canada.
} 
achieves after the hydration process has been completed. Currently, the only way of testing the strength of concrete is through semi-destructive testing on samples rather than, upon the actual structure because of the destructive nature. Electrical methods are the preferred choice for investigating possible innovative methods to achieve this objective. Conduction through concrete is by ionic conduction through the water filled capillary pores (Wilson et al. 1984). High porosity concrete will have a lower resistivity and will also have relatively low mechanical strength.

Previous investigations on electrical methods of characterizing the properties have been carried out on concrete paste by several investigators.

Whittington and Wilson (1986) extended the investigation, with the intention of developing a nondestructive test method for concrete using the measurement of electrical properties.

Tashiro et al. (1987) investigated the dependence of the electrical resistivity on the evaporable and pore size distribution of hardened cement paste. McCarter et al. (1988) suggested the possibility of using cement paste as an advanced electrical material, possibly with mixed with conducting particles to vary the resistivity. The plot of the capacitive reactance against resistance, known as Cole-Cole plot in dielectric theory (Raju 2003) showed the characteristic arc, with a component, part of a much larger arc at lower frequencies.

This research was followed by Wahed and Hekal (1989) who measured the DC conductivity to study the effect of curing media on hardened cement pastes. In a notable contribution Berg et al. (1992) measured the complex impedance of cement paste in the frequency range $10^{-3} \mathrm{~Hz}-10 \mathrm{MHz}$ and identified the influence of various factors such as water/cement ratio and evaporated water.

Wilson and Whittington (1990) extended their AC measurements of dielectric constant and conductivity in the frequency range $1-100 \mathrm{MHz}$ and attempted to explain their results on the basis of Maxwell Wagner theory (Raju 2003). Complex impedance plots experimentally obtained by McCarter (1996) led the authors to suggest that complex impedance plots of concrete, before setting, had the potential for quality control of structural concrete. The investigations of Khalaf and Wilson (1999) considered the use of electrical measurements to determine the movement and special distribution of water within freshly mixed concrete. Manchiryal and Neithalth (2008) observed the effect that changing the water/cement ratio, fly ash content, aggregate/cement ratio and aggregate size had on the dielectric response of cement paste and concrete.

\section{Relevant Electrical Properties}

Concrete was represented by an equivalent electrical circuit of resistance and capacitance as shown in Figure 1. 
Figure 1. Series - Parallel Equivalent Circuit

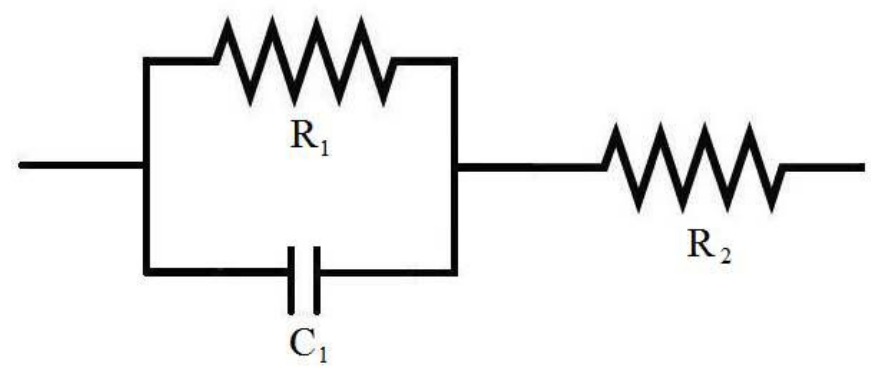

Parallel Circuit in Series with a Resistor

A parallel $R_{1}-C_{1}$ circuit in series with another resistance (R2) may be assumed to model the electrical behavior of concrete. The physical representation of this circuit can be seen in Figure 1. To calculate the total electrical impedance of the parallel circuit in series with a resistor, the first step again is to consider the impedance of each component individually.

The impedance of the resistor in parallel $\left(\mathrm{R}_{1}\right)$ is represented by $\mathrm{Z}_{1}$, the impedance of the capacitor $\left(\mathrm{C}_{1}\right)$ by $\mathrm{Z}_{2}$, and the impedance of the resistor in series $\left(R_{2}\right)$ by $Z_{3}$ while the total impedance of the circuit is represented by the following equation:

$$
Z_{\text {total }}=\frac{Z_{1} Z_{2}}{Z_{1}+Z_{2}}+Z_{3}
$$

Which leads to

$$
Z=\left(\frac{R_{1}}{1+\omega^{2} C_{1}^{2} R_{1}^{2}}+R_{2}\right)-j\left(\frac{\omega C_{1} R_{1}^{2}}{1+\omega^{2} C_{1}^{2} R_{1}^{2}}\right)
$$

Figure 2. Complex Impedance Plot according to Equation (2). C1 $=40 \mathrm{pf}$ for all the Curves

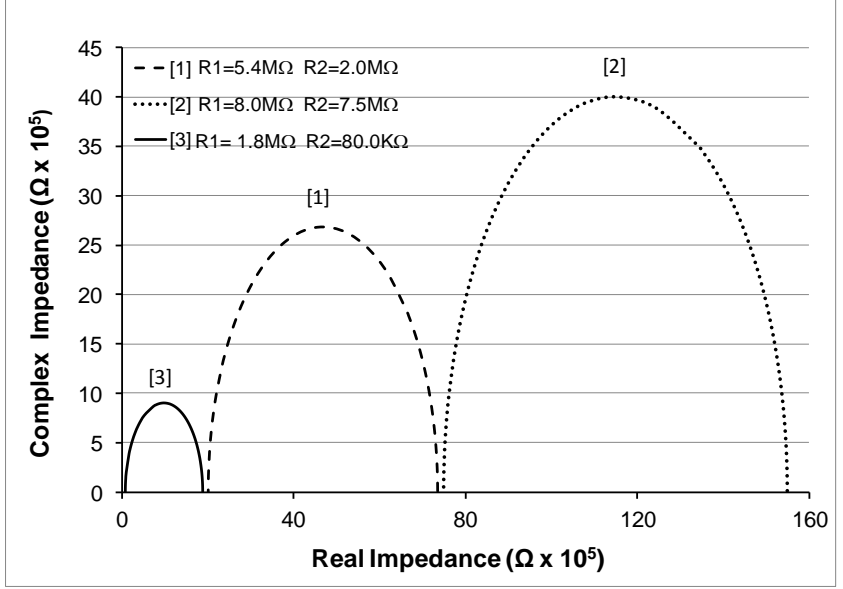

Figure 2 shows the impedance diagram for the circuit of Figure 1. The real part is plotted on the $\mathrm{X}$-axis and the imaginary part on the $\mathrm{Y}$-axis. The impedance signature of the parallel circuit in series with a resistor possesses a parabolic shape where the left intercept with the real axis occurs at the value of 
the resistance $R_{2}$ and the right intercept with the real axis occurs at the value of the real quantity of the impedance found in Equation (2) at zero frequency. All of the plots found in Figure 2 have a capacitance of $40 \mathrm{pF}$, for different values of $\mathrm{R}_{1}$ and $\mathrm{R}_{2}$ as shown.

If the plot designated as [1] is considered as the control plot then it can be seen in Figure 2 that the impedance signature will shift along the real axis and change in amplitude if the values of $\mathrm{R}_{1}$ and $\mathrm{R}_{2}$ are changed. In contrast a small change in capacitance will have little or no effect on the impedance signature, since only a very small increase in amplitude occurs. As seen in plot [2] of Figure 2 an increase in $R_{1}$ and $R_{2}$, causes an increase in amplitude of the impedance plot while also shifting the impedance plot to the right along the real axis beyond the right intercept of plot [1]. It should be noted that these values are theoretical and were selected to demonstrate the shift of plot [2] beyond the right intercept of plot [1]. When considering plot [3] in Figure 2 it can be seen that if the values of $R_{1}$ and $R_{2}$ decrease then the amplitude of the impedance plot will decrease and the plot will shift to the left along the real axis.

\section{Experimental Apparatus and Method}

\section{Electrical Instrumentation}

The electrical data acquired in the experimental program was obtained using a Keithley 3300 LCZ meter (60-100 kHZ), HP LCR bridge 4325 A $10^{4}$ $-10^{7} \mathrm{~Hz}$, DC capacitance meter (Data Precision $93 \mathrm{~B}$ ), (Figure 3) which uses alternating current to measure multiple electrical parameters over a frequency range of $40 \mathrm{~Hz}$ to $100 \mathrm{kHz}$ (Clements 2010). Symbol LCZ stands for inductance $(\mathrm{L})$, capacitance $(\mathrm{C})$, and impedance $(\mathrm{Z})$ which are the primary variables measured by the instrument.

Figure 3. Electrical instrumentation

(a) HP LCZ meter

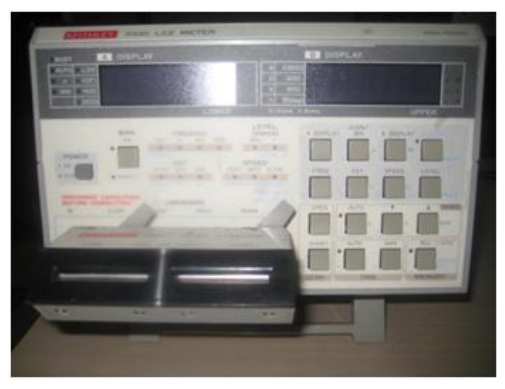

(b) Keithley instrument connected to a sample

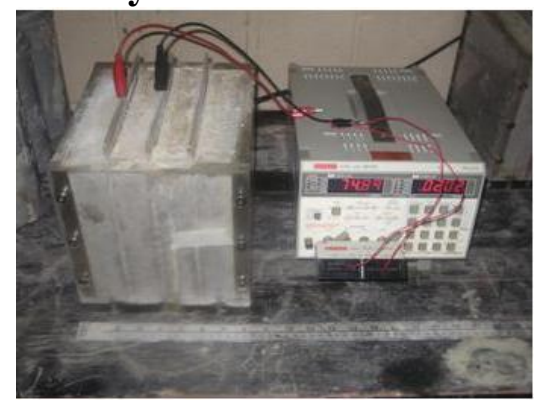

The electrical properties of the concrete were measured everyday beginning from day 2 after the concrete sample was cast until day 28 after the cast. The LCZ meter was used to obtain several electrical parameters of the concrete between the electrodes including capacitance $(C)$, resistance $(R)$, magnitude of impedance $(Z)$, phase angle $(\theta)$, and dissipation factor $(D)$. During Phase I, 
each parameter was measured over a frequency range of 0 to $10 \mathrm{MHz}$ for each day of the 28-day cycle beginning from day 2.

After completing Phase I, it was apparent that a smaller frequency range for testing is acceptable, therefore a frequency range of 120 to $100 \mathrm{kHz}$ was used in Phase II. After further investigation it was found that only one frequency (1 $\mathrm{kHz}$ ) is adequate for the duration of the experimental program, therefore Phase III was completed using a frequency of $1 \mathrm{kHz}$ for each sample over 28 day cycle.

\section{Concrete Materials}

The concrete and cement paste samples used in this study consisted of the following components: cement, sand, coarse aggregate and ordinary drinking water. The mixes used in this study incorporated a coarse aggregate with the minimum grain size of $2.36 \mathrm{~mm}$ (Sieve No. 8) and a maximum grain size of 9.5 $\mathrm{mm}$ (Sieve. No. 3/8 in). The results of the three sieve analyses along with the average values are given in Figure 4.

Figure 4. Results of Sieve Analysis on Coarse Aggregate

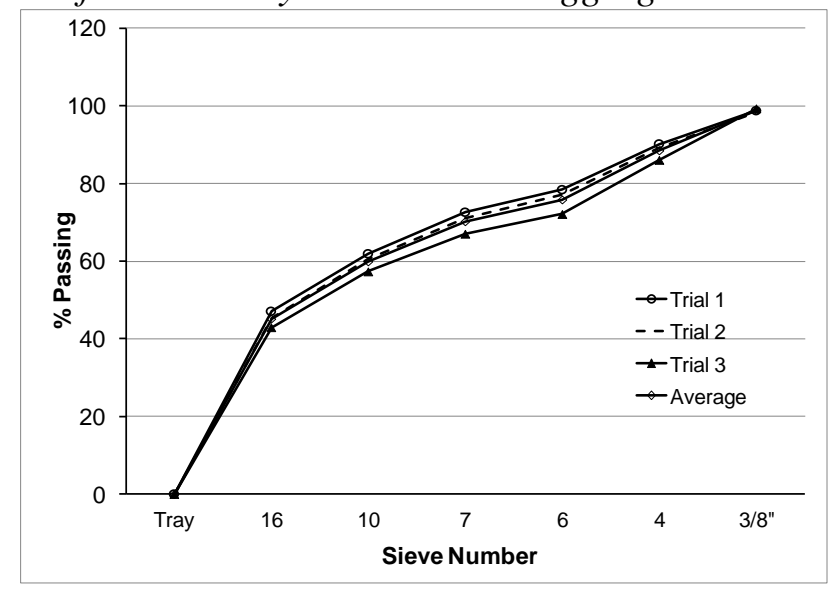

\section{Concrete and Cement Paste Mixes}

Three different concrete mix trials were conducted in order to find the optimum concrete mix for each phase of the study. Each component of the concrete mix was measured accurately using a scale (accurate to $0.1 \mathrm{~g}$ ). The trial mixes were then poured into a mould and removed after 24 hours to determine the qualities of each mix. All of the mixes were cast in $50 \mathrm{~mm}$ steel cube moulds. A base mix (A1) was established using a cement: sand: coarse aggregate $(\mathrm{C}: \mathrm{S}: \mathrm{A})$ ratio of $1: 2: 3$ and a $\mathrm{W} / \mathrm{C}$ ratio by weight of 0.5 .

In most civil engineering construction, a W/C ratio of 0.4 to 0.6 is chosen when no admixtures are used. Hence, in this study, a W/C ratio of 0.5 was chosen as the reference value. It was found that a W/C of 0.5 provided a mix with good workability and consistency. Along with this base mix several other mixes (A2 to A5) were cast with the same C: S: A ratio but with different W/C ratios in order to determine the best possible mix. 
The concrete samples were removed from the non-absorbent moulds after one day to investigate the quality of each concrete mix. After inspecting each specimen it was found that each mix produced an excess of voids around the surface of the mould. This indicated that the amount of coarse aggregate in the mix required reduction in the next trial of concrete composition. The mixes of Trial II are shown in Table 1. Figure 5 shows the different types of moulds used in the study.

Table 1. Concrete Mixes of Trial II

\begin{tabular}{|c|c|c|c|c|c|c|c|c|}
\hline \multirow{2}{*}{ Material } & \multicolumn{2}{|c|}{ Base mix B1 } & \multicolumn{2}{|c|}{ B2 } & \multicolumn{2}{|c|}{ B3 } & \multicolumn{2}{|c|}{ B4 } \\
& $(\mathrm{g})$ & $\begin{array}{c}\mathrm{Wt} \\
\%\end{array}$ & $\begin{array}{c}\mathrm{Wt} \\
(\mathrm{g})\end{array}$ & $\begin{array}{c}(\mathrm{Wt} \\
\%\end{array}$ & $\begin{array}{c}\mathrm{Wt} \\
(\mathrm{g})\end{array}$ & $\begin{array}{c}\mathrm{Wt} \\
\%\end{array}$ & Weight $(\mathrm{g})$ & Weight $\%$ \\
\hline Cement & 60 & 19.61 & 72 & 23.53 & 84 & 27.45 & 79.8 & 26.08 \\
\hline Sand & 102 & 33.33 & 114 & 37.25 & $\begin{array}{c}12 \\
6\end{array}$ & 41.18 & 126 & 41.18 \\
\hline $\begin{array}{c}\text { Coarse } \\
\text { aggregat } \\
\text { e }\end{array}$ & 108 & 35.03 & 84 & 27.45 & 60 & 19.61 & 60 & 19.61 \\
\hline Water & 36 & 11.76 & 36 & 11.76 & 36 & 11.76 & 40.2 & 13.14 \\
\hline $\begin{array}{c}\text { W/C } \\
\text { Ratio }\end{array}$ & \multicolumn{2}{|c|}{0.6} & \multicolumn{2}{|c|}{0.5} & \multicolumn{2}{|c|}{0.43} & \multicolumn{2}{|c|}{0.5} \\
\hline $\begin{array}{c}\text { C:S:A } \\
\text { ratio }\end{array}$ & \multicolumn{2}{|c|}{$1: 1.7: 1.8$} & \multicolumn{2}{|c|}{$1: 16: 1.16$} & $1: 1.5: 0.7$ & \multicolumn{2}{|c|}{$1: 1.6: 0.75$} \\
\hline
\end{tabular}

Figure 5. Various Moulds used in this Study

\section{(a) Concrete cube with face electrodes}

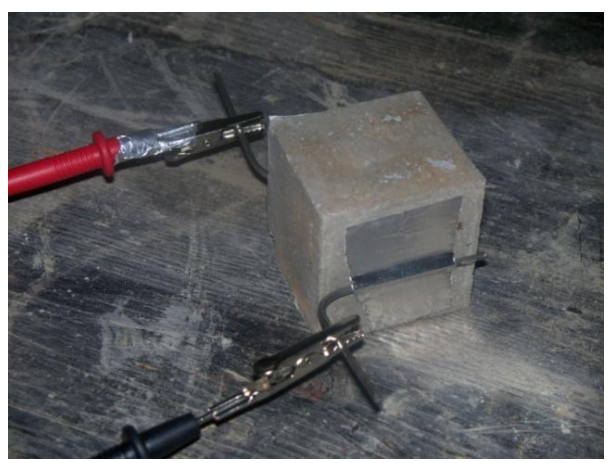

(b) Mould designated as I

\section{(c) Mould designated as II}

(d) Mould designated as III
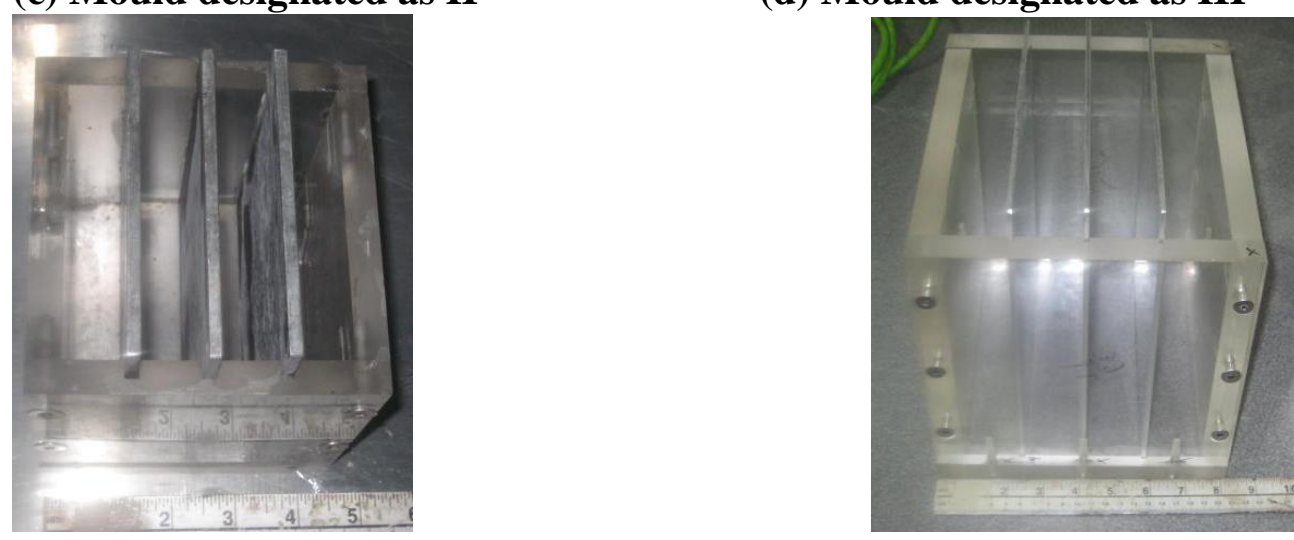


\section{Test Matrix}

Only part of the test matrix chosen in this study is shown in Table 2 for lack of space. Designation of each specimen is chosen such that it identifies most important attributes of the specimen. The first Roman number (I or II) indicates the type of mould used (Figure 5); The next Roman number (I) represents the type of concrete mix used in this samples is Type I which was mixed with cement: sand: aggregate of 1:1.6:0.75 with water-cement ratio of 0.5 ; the next number ( 20 or 40 ) indicates that the centre-to-centre distance between two adjacent electrodes in $\mathrm{mm}$; the next word (All) indicated that all the three identical specimens (A, B, and C) are considered; and the last Roman letter (I) is used to indicate that the specimen belongs to a testing Phase I. It should be noted that internal dimensions of the moulds were $50 \mathrm{~mm}$ x $50 \mathrm{~mm}$ x $50 \mathrm{~mm}$ for Type I and $100 \mathrm{~mm}$ x $100 \mathrm{~mm}$ x $100 \mathrm{~mm}$ for Type II. Hence, II-A20-ABC-I indicates the fact the these specimens were made in mould Type I (50 $\mathrm{mm}$ x $50 \mathrm{~mm} \times 50 \mathrm{~mm}$ ) using concrete mix I.

Table 2. Part of Test Matrix

\begin{tabular}{|c|c|c|c|c|c|c|}
\hline \multirow[b]{2}{*}{$\begin{array}{l}\text { Test } \\
\text { Phase }\end{array}$} & \multicolumn{3}{|c|}{ Electrical Specimens } & \multicolumn{3}{|c|}{ Concrete Cylinders } \\
\hline & Designation & $\begin{array}{c}\text { Number } \\
\text { of } \\
\text { specimens }\end{array}$ & $\begin{array}{c}\text { Testing } \\
\text { days }\end{array}$ & $\begin{array}{c}\text { Testing } \\
\text { days }\end{array}$ & $\begin{array}{l}\text { Number of } \\
\text { cylinders/day }\end{array}$ & $\operatorname{mix}$ \\
\hline \multirow{3}{*}{ I } & I-A-20-All-I & 3 & \multirow{3}{*}{ Days 2-28 } & \multirow{3}{*}{$\begin{array}{l}2,7,14, \\
21 \& 28\end{array}$} & \multirow{3}{*}{4} & \multirow{3}{*}{ I } \\
\hline & II-A-20-All-I & 3 & & & & \\
\hline & II-A-40-All-I & 3 & & & & \\
\hline
\end{tabular}

Phase I consisted of electrical and compression testing on concrete samples that were cast in the concrete moulds and plastic cylinders simultaneously using Concrete Mix I. Slump testing was performed on a sample of each concrete batch before casting and density testing of the cylinders was performed on the same day prior to compression testing. Phase II involved electrical testing on Cement Paste Mix I and Cement Paste Mix II, while the cement paste mixes were not tested for strength and density. Phase III consisted of electrical testing on specimens cast in Concrete Mould II using Concrete Mix II and specimens cast in Concrete Mould III using Concrete Mix I (not shown).

\section{Experimental Results}

The results in this section pertain to the cylinder compression testing and electrical testing. The results and their analyses are presented for each phase.

\section{Phase I Results}

Phase I used two different moulds: Type I and Type II with two different electrode spacing: $20 \mathrm{~mm}$ and $40 \mathrm{~mm}$. However only one concrete mix (Concrete Mix I or A) was used, as shown in Table 2. 


\section{Slump and Density}

The slump test on concrete mix I was performed and it produced a slump of $100 \mathrm{~mm}$, which is considered to be moderate in terms of workability. The density of each cylinder was calculated prior to capping and the values of the densities and the average density obtained at each test day was determined.

\section{Compression Strength}

The ultimate compressive stress (it is called strength in subsequent discussion) generally increases with time with the exception occurring with the curve for day 2 as the curve does not follow the general trend. While it can be noted that compression testing is rarely executed on concrete at such a premature age due to the fact that concrete at that early stage does not achieve sufficient hydration and testing results can be erratic. However, from the test data of this study it can be concluded that the strength of the concrete increases with time.

\section{Electrical Testing Results}

As outlined in section 3 electrical tests were performed over a large frequency range in Phase I. However, after a careful analysis and study of all the test results, it was found that the results at the frequency $(f)$ of $1000 \mathrm{~Hz}$ were the most useful in this study. Among the measured parameters including capacitance $(C)$, resistance $(R)$, magnitude of impedance $(Z)$, phase angle $(\theta)$, and dissipation factor (D) it was found that the capacitance $(C)$ was the most relevant measured parameter and provided the most interesting result when it was transformed into the imaginary value of impedance called reactance $(\mathrm{X})$. This was due to the fact that the variance of the other parameters between specimens of the same type was found to be higher than the variance seen in the reactance of the specimens. The reactance was calculated, assuming that the concrete specimens can be modeled using a series circuit. The use of the frequency $(f)$ of $1000 \mathrm{~Hz}$ was determined after plotting the reactance of specimen I-A-20-A-I with time at different frequencies.

As seen in Figure 6 the frequency does not affect the shape of the reactance-time curve, thus it is concluded that a convenient frequency of 1000 $\mathrm{Hz}$ could be chosen without changing the results of the study. A frequency of $1000 \mathrm{~Hz}$ was chosen due to the fact that it produced reliable results within a larger range of reactance values than other frequencies, while also producing minimal variance in reactance between specimens of the same type. Also, it was observed that the electrical parameters measured at higher frequencies became erratic when compared to $1000 \mathrm{~Hz}$. Therefore, all of the reactance values reported in this paper were calculated at the frequency $(f)$ of $1000 \mathrm{~Hz}$.

There were three specimens cast for both mould types in Phase I with three different types of specimens used including: I-A-20-All-I, II-A-20-All-I and IIA-40-All-I. This resulted in the testing of mould type I with only one electrode distance of $20 \mathrm{~mm}$ and the testing of mould type II with two different electrode distances. After calculating the average (average value of the three specimens) 
reactance for each specimen type the reactance was plotted for the frequency of $1000 \mathrm{~Hz}$ over time and can be seen in Figure 7.

Figure 6. Reactance vs. Time for Sample I-A-20-A-I

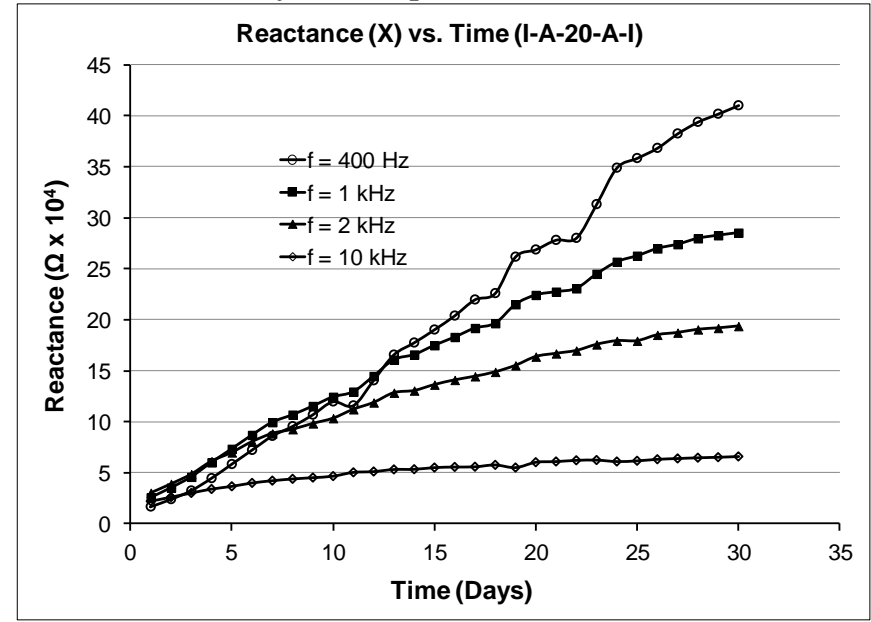

Figure 7. Reactance vs. Time Phase I

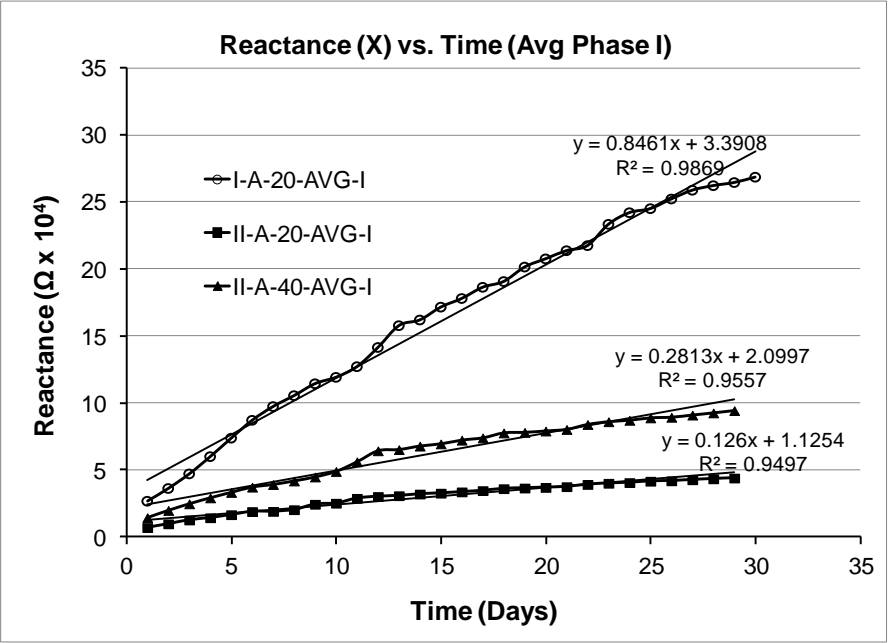

From Figure 7 it is seen that an increase in cross-sectional area (A) of the concrete specimen decreases the reactance of the concrete. It can also be seen that an increase in electrode distance (d) caused an increase in reactance, as specimens II-A-20-AVG-I and II-A-40-AVG-I differ only in electrode distance representing $20 \mathrm{~mm}$ and $40 \mathrm{~mm}$, respectively. The word $A V G$ stands for Average and hence these plots are made for average values obtained from three identical samples (A, B, and C). A linear regression analysis was performed on each specimen resulting in an equation for calculating the reactance $(\mathrm{X})$ if the time $(\mathrm{t})$ is known. Each specimen resulted in $\mathrm{R}^{2}$ values of $0.9869,0.9497$, and 0.9557 as shown in Figure 7. Hence, the linear regression analyses for the test data provide a statistically acceptable fit. The equation for a specimen is as follows. 
For I-A-20-AVG-I:

$$
X=8461.5 t+33908
$$

Similar equations have been obtained for all specimens investigated.

Analysis of Phase I Results

Since the equations for the reactance $(X)$ and concrete strength $\left(f_{c}\right)$ both depend on the variable of time linearly, the equations can be arranged to result in a certain reactance representing a corresponding strength. The equations for the strength of concrete $\left(f_{c}\right)$ in terms of reactance $(X)$ for each specimen tested in Phase I are obtained. For example:

For I-A-20-AVG-I:

$$
f_{c}=4.807 \times 10^{-5}(X)+30.13
$$

For II-A-20-AVG-I:

$$
f_{c}=3.229 \times 10^{-4}(X)+28.13
$$

For II-A-40-AVG-I:

$$
f_{c}=1.446 \times 10^{-4}(X)+28.73
$$

$\mathrm{f}_{\mathrm{c}}=$ concrete strength $(\mathrm{MPa})$

A plot of equations (4) through (6) can be seen in Figure 8, where the reactance values used are the values obtained experimentally. Each point on the linear plot corresponds to one day in the concrete curing life.

Figure 8. Concrete Strength vs. Reactance in Phase I

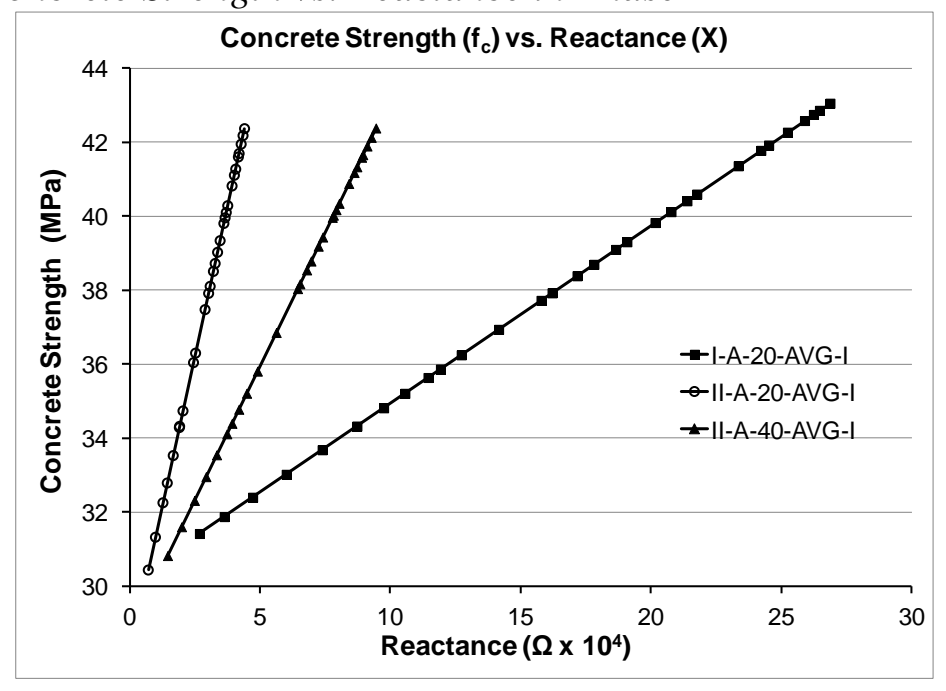

As it can be seen in Figure 8, each specimen type represents a distinctly different linear plot denoting the concrete strength $\left(f_{c}\right)$ in terms of reactance (X). Specimen I-A-20-AVG-I represents the plot with the lowest slope, while specimen II-A-20-AVG-I represents the plot with the highest slope. Therefore, the slope of the strength-reactance plot increased as the cross-sectional area (A) of the mould increased. It can also be seen in Figure 8 that specimen II-A-20AVG-I has a higher slope than specimen II-A-40-AVG-I. Therefore, the slope of the strength-reactance plot decreased as the electrode distance increased. 
Although the relationship between concrete strength and reactance can be established, equations (4) to (6) are considered valid only for concrete mix I as seen in Table 1 (Sample mix B4) for a reactance calculated at $f=1000 \mathrm{~Hz}$ and for the corresponding dimensions of each mould. A large number of tests need to be completed in order to develop a generic universal equation relating concrete strength to reactance as there may be a number of other variables which may affect the reactance of a concrete.

\section{Conclusions}

Based on the results obtained in this study the following conclusions were made. It must be noted that the conclusions made here only pertain to the concrete mixes and mould sizes used in this study.

- The strength of concrete can definitely be related to the reactance of concrete, since both of the variables vary linearly with time.

- The reactance of the concrete increases if the electrode distance in the concrete mould increases.

- The reactance of the concrete decreases if the electrode contact area in the concrete mould increases.

- The reactance of the concrete decreases if the cement content of the concrete decreases.

- The reactance of concrete is not greatly affected by frequency as the shape of the reactance-time curve does not change with frequency.

\section{References}

Berg, A., Niklasson, G. A., Brantervik, K., Hedberg, B. and Nilsson, L. O. , 1992, "Dielectric Properties of Cement Mortar as a Function of Water Content." J. Appl. Phys., American Phys. Inst., Vol. 71, No. 12, pp. 58975903, 1992.

Clements, W., 2010, “Application of Electrical Methods to Assess the Quality of Concrete,” M. A. Sc. Thesis, University of Windsor.

Khalaf, F. M.., and J. G. Wilson, 1999, "Electrical properties of freshly mixed concrete." Journal of Materials in Civil Engineering, American Society of Civil Engineers, vol. 11, no. 3, pp 242-248.

Manchiryal, R.K., and Neithalath, N., 2008, "Electrical property-based sensing of concrete: influence of material parameters on dielectric response." American Concrete Institute, ACI Special Publication, no. 252, pp 23-40.

McCarter,W.J., 1996, "The a.c. impedance response of concrete during early hydration." Journal of Materials Science, Springer US, vol. 31, no. 23, pp 6285-6292. 
McCarter, W.J., Garvin, S., and Bouzid,N. , 1988, "Impedance measurements on cement paste." Journal of Materials Science Letters, Springer US, vol. 7, no. 10, pp 1056-1057.

Raju, G. G., "Dielectrics in Electric Fields.” 2003, Marcel Dekker, New York, 2003.

Tashiro, C., Ishida, H., and Shimamura, S., 1987, "Dependence of the Electrical Resistivity on evaporable Water Contenr in Hardened Cement Pastes." Journal of Material Science Letters, Springer U. S., Vol. 6, No. 12, pp. 1379-81.

Wahed M. G. A. and E. E. Hekal, 1989, "Electrical Conductivity of Cement Pastes, in Different Curing Media," J. Mat. Sci. Lett., 8, pp. 875-878.

Whittington, H.W., and Wilson, J.G., 1986, "Low-frequency electrical characteristics of fresh concrete." IEE Proceedings A (Physical Science, Measurements, Instrumentation, Management \& Education, Reviews), Institution of Electrical Engineers, Lancaster, UK, Vol. 133, no. 5, pp 265271.

Wilson J. G., H. W. Whittington and M. C. Forde, "Dielectric Properties of Concrete at Different Frequencies." Fourth International Conference on Dielectric Materials. Measurements and Applications," Lancaster, U. K., pp. 157-160, 1984. 